\title{
TAKEDA V. RIMSA. MÉXICO, EL CONVENIO DE PARÍS, EL ADPIC Y EL TCP
}

\author{
TAKEDA V. RIMSA. MEXICO, THE PARIS CONVENTION, THE \\ TRIPS AND THE PCT
}

\section{ROBERTO GarZa BARBOSA ${ }^{*}$}

\begin{abstract}
RESUMEN: El presente ensayo aborda un litigio sobre la infracción de una patente iniciado por una empresa japonesa en México. El litigio estaba basado en un título de patente obtenido en México gracias a que se reconoció una fecha de prioridad siete años después. Otro aspecto del litigio es que el mismo involucró la extensión de la vigencia de dicha patente, así como la infracción alegada posteriormente a la extensión del término de protección. Se abordan varios temas desde la perspectiva de derecho internacional y el derecho comparado. Los mismos van desde principios de independencia de las patentes, trato nacional, así como el término mínimo de protección. Es decir, se analiza la aplicación del Convenio de París, el ADPIC así como del Tratado de Cooperación en Materia de Patentes.
\end{abstract}

Palabras clave: Litigio de Patente, TCP, Trato Nacional, Patente, México.

\begin{abstract}
This essay analyzes a patent litigation in Mexico. The plaintiff was a Japanese company and it was suing over the infringement of its rights by a Mexican Lab. In this case, the Mexican Industrial Property Statute was applied as to recognize a priority filing date seven years later from its original filing in Japan. The litigation involved several subjects like the extension of the term of protection, and the alleged infringement made by defendant after authorities extended the protection term of the patent. There are several issues and principles discussed, like the principle of independence of patents, national treatment, and minimum term of protection; all contained in the Paris Convention, TRIPs agreement and also the Patent Cooperation Treaty.
\end{abstract}

Key words: Patent Litigation, PCT, National Treatment, Patent, Mexico.

\section{INTRODUCCIÓN}

La patente objeto del litigio que abordaré en este comentario vencería el 15 de enero de 2006. Sin embargo, su titular a través de un procedimiento contencioso administrativo logró extender su duración. Posterior a ello, demandó a un laboratorio que estaba fabricando y comercializando el medicamento protegido por dicha patente. El laboratorio demandado fabricaba y comercializaba dicho medicamento, debido a que se suponía que esa patente estaría en el dominio público para esas fechas, había una expectativa de derecho.

Originalmente, la invención provenía del Japón, su titular, una empresa farmacéutica denominada Takeda Pharmaceutical Company Limited (Takeda) presentó en aquél país

\footnotetext{
* Profesor Investigador, Departamento de Derecho, Tecnológico de Monterrey. Doctor en Derecho Internacional y Comparado, Universidad de Tulane (Nueva Orleáns, EE.UU., 2006). Dirección postal: Eugenio Garza Sada 2501 sur, Monterrey, México. Dirección electrónica: rgb@itesm.mx.
} 
dos solicitudes, la primera fechada el 19 de enero de 1985, misma que fue desistida en favor de otra solicitud de fecha 9 de enero de $1986^{1}$. Es decir, estamos frente a una fecha de solicitud en Japón de 1985, prioridad hecha valer en México hasta 1992. Lo anterior, por supuesto, no refleja el curso normal de una solicitud internacional, ya sea utilizando los principios del Convenio de París para la Protección de la Propiedad Industrial (Convenio de París) ${ }^{2}$, o del Tratado de Cooperación en Materia de Patentes (TCP)3․ En 1986, no intentaron su registro en México debido a que la normativa nacional no preveía protección de patente para productos farmacéuticos.

La diferencia de años entre las solicitudes japonesas y la fecha de solicitud en México plantea un problema de novedad, requisito fundamental para obtener una patente. Es decir, para obtener protección, la invención se sopesa contra el estado de la técnica, que es global. Entonces, si se determina que el invento ya ha sido publicado, comercializado, o utilizado anteriormente en cualquier parte del mundo, el mismo carecerá de la novedad requerida y la patente será negada. Incluso, actos propios del inventor pueden ocasionar que se pierda la novedad.

Así, para 1992, fecha de la solicitud en México, la novedad requerida ya se había perdido, debido a que diversas solicitudes de patente sobre la invención habían sido publicadas un sinnúmero de veces. Comenzando por su país de origen, por el mecanismo TCP, además de las publicaciones hechas en todos los países en los que se procuró la protección de dicha invención ${ }^{4}$.

En este punto entra a la escena un precepto normativo que es parte central del litigio. Se trata del artículo décimo segundo transitorio de la Ley de la Propiedad Industrial, ya que de no haber sido por dicho precepto, la patente en cuestión no se hubiese otorgado por no cumplir con el requisito de novedad ${ }^{5}$. El mencionado artículo transitorio creó un régimen excepcional para este tipo de invenciones, en especial aquellas que no cubrirían el requisito de novedad por haber sido publicadas previamente en sus países de origen, durante el proceso de obtención de la patente ${ }^{6}$. Específicamente, el artículo décimo segundo transitorio beneficia a productos farmacéuticos e invenciones que la abrogada normativa no protegía por medio de patente, sino a través del extinto certificado de invención ${ }^{7}$. Los requisitos son los siguientes: que la solicitud original se haya presentado en algún país miembro del TCP, que se haya realizado dentro de los 12 meses contados a partir de que

\footnotetext{
1 Práctica común en algunos sistemas jurídicos. LEMLEY y MOORE (2004) p. 94; SHINALL (2012) p. 374.

2 Convenio de París para la Protección de la Propiedad Industrial, Estocolmo (28 de septiembre de 1979).

3 Tratado de Cooperación en Materia de Patentes, Washington (19 de junio de 1970).

4 FARRAND (2006) p. 1266.

5 SOlOVy y Krishnamurthy (2017) p. 96. Para ilustrar lo anterior, tenemos que una solicitud para proteger la misma invención denominada Derivados de Tiazolidina, fue desechada por el Instituto Nacional de Propiedad Industrial INAPI de Chile el 6 de abril de 2001. Disponible en: https://ion.inapi.cl/Patente/ConsultaAvanzadaPatentes.aspx. Fecha de consulta: 6 de enero de 2018.

6 TOBIAS et al. (2009) p. 115; PIL (2014) p. 358.

7 LEY DE INVENCIONES Y MARCAS (abrogada), México (10/02/1976), arts, 10 y 65.
} 
entró en vigor la Ley de la Propiedad Industrial, y que la invención no se haya explotado o importado a escala comercial en el país.

$\mathrm{Al}$ establecer como requisito que la solicitud original haya sido presentada ante algún país miembro del TCP, se podría pensar que el artículo décimo segundo transitorio de la Ley de la Propiedad Industrial se refiere a solicitudes que vienen de la fase de búsqueda internacional del TCP. Sin embargo, al analizar sus términos, vemos que no se trata de este tipo de solicitudes ${ }^{8}$, debido a que el precepto legal refiere tanto solicitudes hechas, como a patentes otorgadas.

Si bien el artículo décimo segundo transitorio de la Ley de la Propiedad Industrial creó una oportunidad para ciertas invenciones, también trajo consigo un enorme problema, ya que ligó la fecha de finalización del término de protección en México, con la respectiva fecha de finalización en el país de origen: "Las solicitudes de patente presentadas antes de la fecha en que esta Ley entre en vigor, en cualquiera de los países miembros del [TCP] [...] mantendrán en México la fecha de prioridad de la primera solicitud presentada [...] La vigencia de las patentes que fueren otorgadas al amparo de este artículo terminará en la misma fecha en que lo haga en el país donde se hubiere presentado la primera solicitud, pero en ningún caso la vigencia excederá de 20 años, contados a partir de la fecha de presentación de la solicitud de patente en México"?.

La contrariedad surge debido a que el artículo décimo segundo transitorio de la Ley de la Propiedad Industrial dispone un término de protección diferente al señalado por el artículo 23 de dicha normativa. De acuerdo al artículo 23 de la Ley de la Propiedad Industrial, la vigencia de una patente de invención es de 20 años improrrogables, que comienzan a partir de la fecha de presentación de la solicitud en México. Consecuentemente, si la fecha de solicitud de la patente objeto de la controversia fue el 17 de junio de 1992, entonces la fecha de vencimiento tendría que haber sido el 17 de junio de 2012. Máxime si dicho precepto legal ha permanecido sin cambio alguno desde la publicación de la propia Ley de la Propiedad Industrial en el Diario Oficial de la Federación el 27 de junio de $1991^{10}$. Sin embargo, las patentes obtenidas bajo el esquema del artículo décimo segundo transitorio de la Ley de la Propiedad Industrial, no se les aplica el término de protección establecido por el artículo 23 de la misma normativa, que en este caso se habría traducido a un vencimiento el 17 de junio de 2012 y no el 15 de enero de 2006 fecha originalmente señalada en el título. Más aún, ni con la extensión de la vigencia ordenada en el procedimiento contencioso administrativo al que me refiero en el primer párrafo, se llega al término establecido por el artículo 23 de la Ley de la Propiedad Industrial.

En otro orden de ideas, es importante señalar que se trata de un litigio complejo. Ello, derivado de las enormes ganancias que el medicamento protegido por la patente objeto de la controversia, representaría tanto para el actor como para el demandado. El litigio comprende más de 16 resoluciones, ambas partes mostraron una holgada línea de argumentación y técnica, agotando todos los recursos y juicios que tuvieron a su disposi-

\footnotetext{
8 LAPENNE (2010) p. 198.

9 Ley de la Propiedad Industrial, México (27/06/1991), artículo décimo segundo transitorio.

10 Diario Oficial de la Federación, México (27/06/1991).
} 
ción. Sin embargo, el presente comentario analiza solamente las resoluciones medulares, las más relevantes.

A diferencia de la mayoría de los sistemas jurídicos en donde el litigio de la propiedad intelectual se lleva ante un juzgado ordinario dentro de la esfera judicial, en el sistema jurídico mexicano la infracción de patentes y marcas se litiga ante la misma autoridad administrativa que emite sus registros. Lo anterior complica el litigio debido a la dificultad de acumular diversas acciones en un solo procedimiento, además existen diversos recursos y acciones que los litigantes tienen a su disposición para combatir las sentencias desfavorables.

El presente comentario, aborda una serie de temas relacionados con el litigio en cuestión. Intrínsecamente, y de manera empírica, ilustra cómo son este tipo de procedimientos en el sistema jurídico mexicano. Además, analiza la interpretación, así como la ignorancia por parte de más de un juzgador, de varios principios contenidos en diversos tratados internacionales aplicables sobre propiedad intelectual. Principios como la independencia de las patentes y el trato nacional, contenidos ambos en el Convenio de París ${ }^{11}$, como también el término mínimo de protección de las patentes contenido en el Acuerdo sobre los Aspectos de los Derechos de Propiedad Intelectual relacionados con el Comercio $(\mathrm{ADPIC})^{12}$

Cada capítulo analiza la resolución en una instancia con su razonamiento, además de los argumentos de las partes. Se comienza con una explicación general de la problemática que enfrentan los inventores al intentar obtener protección de una invención a nivel internacional, así como la respuesta que los tratados internacionales han establecido para aminorar el enorme reto que significa proteger una invención a nivel global. Se continúa con los antecedentes del litigio y el problema de la extensión del término de protección. Sigue el análisis de cada instancia, hasta llegar a la Suprema Corte de Justicia de la Nación.

\section{DERECHO INTERNACIONAL}

El presente comentario analiza una cuestión muy intrínseca dentro del sistema jurídico mexicano, un litigio. Pero antes de pasar al estudio de tan específica y particular cuestión, es necesario analizar de manera general, algunos antecedentes de importancia e interés acerca de los tratados internacionales aplicables.

El primero de ellos es el Convenio de París. Surge como respuesta a los inconvenientes derivados de un principio fundamental de la propiedad intelectual, su territorialidad. Lo anterior significa que la normativa nacional de cada país solamente otorga protección dentro de su respectivo territorio, dejando desprotegida la propiedad intelectual nacional en el resto del orbe. Ello, ocasionó que ciertas personas, aprovechándose de dicha territorialidad, copiaran invenciones en el extranjero, principalmente en exposiciones de tecnología, y a su regreso al país de origen, registraran aquello como invención propia.

11 Convenio de París para la Protección de la Propiedad Industrial, Estocolmo (28 de septiembre de 1979).

12 Acuerdo sobre los Aspectos de los Derechos de Propiedad Intelectual relacionados Con EL COMERCIO, Marrakech (15 de abril de 1994). 
Sumado a lo anterior, obtener protección en el extranjero se tornaba extremadamente difícil, o imposible, ya que la novedad, un requisito esencial y emblemático de las patentes, era sopesada de manera diferente en cada país. Incluso, algunas jurisdicciones llegaron al absurdo de considerar que la solicitud sobre el mismo invento presentada por el propio inventor en su país de origen el día anterior a la fecha de solicitud nacional, evitaría que la invención fuese considerada novedosa ${ }^{13}$. Una exagerada apreciación del estado de la técnica. Para evitar lo anterior, se tenía que presentar la solicitud simultáneamente el mismo día en todos los países en los en que se deseara protección. Lo monumental de la tarea se puede visualizar mejor si consideramos que la primera versión del Convenio de París entró en vigor en 1883 .

El propósito fundamental del Convenio de París fue precisamente sortear lo anterior a través de diversos principios. El primero de ellos es el trato nacional ${ }^{14}$. Además, establece definiciones y parámetros mínimos de protección. Sin embargo, la protección otorgada nunca ha sido automática, de manera que, el inventor tendría que solicitarla país por país. Para facilitar las solicitudes en diversos países, el Convenio de París establece el principio de prioridad reconocida, extendiéndose 12 meses para patentes de invención y seis meses para marcas, desde la fecha de la primera solicitud ${ }^{15}$. Ello significa que, cualquier solicitud del propio solicitante posterior a la fecha de primera solicitud, en algún país miembro dentro del periodo señalado, no podrá ser invalidada o negada, ya sea por alguna solicitud previa presentada por un tercero en ese país, o por la propia publicación de la solicitud en el país de origen, o por la comercialización del producto $^{16}$. Es decir, protege la prioridad en relación a posibles solicitudes que hagan terceros y protege la novedad de la invención, que se pueda perder por la propia solicitud original, o la comercialización del producto por parte del propio solicitante.

Transcurridos los 12 meses desde la fecha prioridad reconocida, la propia solicitud original de patente ocasionaría que se pierda la novedad de la invención en el extranjero ${ }^{17}$. El dilema se deriva del hecho que la propiedad intelectual es territorial, pero el estado de la técnica es global. Aunque las patentes sean otorgadas por oficinas nacionales y su alcance esté constreñido a su país, la publicación de la solicitud por parte de la oficina nacional provocará que la invención ya no sea novedosa en una posterior solicitud que se haga en otro país. Esto se debe a que, en la generalidad de los países, una vez que se solicita la patente, se hace una publicación de dicha solicitud a los 18 meses de la fecha de prioridad

13 Mueller (2009) p. 525.

14 Convenio de París para la Protección de la Propiedad Industrial, Estocolmo (28 de septiembre de 1979), art. 2.

15 Convenio de París para la Protección de la Propiedad Industrial, Estocolmo (28 de septiembre de 1979), art. 4.

16 Convenio de París para la Protección de la Propiedad Industrial, Estocolmo (28 de septiembre de 1979), art. 4(B).

17 Lo anterior ocurre en la generalidad de las jurisdicciones. Para ilustrar lo anterior en el sistema jurídico chileno, véase LEY $\mathrm{N}^{\circ} 19.039$ de 2006, art. 33. 
reconocida ${ }^{18}$, si no es que antes. Además, se publica el título una vez otorgada, junto con la solicitud y las reivindicaciones solicitadas. Es por eso que, la patente se debe solicitar en todos los países en los que se desea obtener protección casi al mismo tiempo.

Aquí viene a colación el TCP, que fue negociado a iniciativa de la Organización Mundial de la Propiedad Intelectual (OMPI). Sus objetivos son: la simplificación y uniformidad de los diversos procedimientos de aplicación de patente nacionales mediante un solo formato de aplicación, así como la reducción de costos de patentar invenciones en diversos países. Sin duda, el TCP tuvo éxito en sus cometidos ya que sus países miembros tienen un alto grado de uniformidad en los procedimientos de obtención de las patentes, además de contar con un mismo formato. Asimismo, el TCP ha facilitado la titánica tarea de proteger una invención en varias jurisdicciones.

El procedimiento de consecución de una patente de invención, a través del TCP consta de dos fases: una internacional ante la OMPI y la segunda nacional, en cada uno de los países en que se pretende la protección. La fase internacional comprende: 1) aplicación internacional al TCP, que se puede hacer directamente ante la OMPI, con la opción de realizar dicha solicitud en línea, o a través de las oficinas nacionales de patentes de cada país miembro, que actúan como receptoras encausando la solicitud a la $\mathrm{OMPI}^{19}$; 2) un examen de forma, 3) una búsqueda internacional, sobre la novedad de la invención cuya protección se solicita ${ }^{20}$, 4) publicación internacional a los 18 meses de la fecha de prioridad reconoci$\mathrm{da}^{21}$. Las siguientes dos fases son opcionales: 5) búsqueda internacional suplementaria; y 6) examen preliminar internacional.

Un aspecto de suma utilidad del TCP es que se tiene hasta 30 meses después de la fecha de prioridad o primera solicitud para ir a la fase nacional, país por país ${ }^{22}$. Este término es mucho mayor a los 12 meses otorgados por el principio de fecha de prioridad establecido por el Convenio de París. En este sentido, el artículo 11 del TCP establece que la fecha de presentación internacional, surtirá los efectos de presentación nacional en cada uno de los estados en los que solicite la protección ${ }^{23}$. Por lo tanto, durante estos 30 meses, el solicitante puede evaluar si la invención es lo suficientemente redituable para seguir con la consecución del derecho, además de preparar las traducciones respectivas al idioma de cada uno de los países en los que pretende solicitar la protección ${ }^{24}$. Adicionalmente, el resultado de la búsqueda internacional sobre novedad y estado de la técnica señalada en la etapa 3) de la fase internacional, es altamente persuasivo para las oficinas nacionales, quienes en

18 A manera de ilustración, véase LEY N ${ }^{\circ} 19.039$ de 2006, art. 4, en relación con su REgLAMENTO, art. 14; Ley de Patentes de InVEnción y Modelos de Utilidad, Argentina, (20/03/96), art. 26; Ley N 17.164, DeRechos y Obligaciones Relativos a las PATENTES DE INVENCIÓN, LOS MOdelos de UTILIDAD Y LOS Diseños Industriales, Uruguay, (2/09/99), art. 26; LeY DE LA Propiedad Industrial, México (27/06/1991), art. 52.

19 Tratado de Cooperación en Materia de Patentes, Washington (19 de junio de 1970), arts. 3, 10.

20 Tratado de Cooperación en Materia de Patentes, Washington (19 de junio de 1970), art. 15.

21 Tratado de Cooperación en Materia de Patentes, Washington (19 de junio de 1970), art. 21.

22 Tratado de Cooperación en Materia de Patentes, Washington (19 de junio de 1970), art. 22.

23 Khoury (2012) p. 209.

24 ILARDi y BLAKENEY (2004) p. 40. 
última instancia deciden si otorgan la patente de invención o no. Es decir, se puede realizar una sola aplicación internacional, en un solo idioma, pagar un solo conjunto de derechos y tener por presentada la solicitud en todos los países miembros, presentando la respectiva solicitud en esos países hasta los 30 meses $^{25}$. Además, esta solicitud internacional se puede presentar en línea ${ }^{26}$.

No podríamos concluir esta sinopsis sobre tratados internacionales en materia de patentes, sin mencionar al artículo 27 del ADPIC. El mismo es importante, debido a que, en lo tocante a patentes de invención, el Convenio de París hace un poco más que establecer el trato nacional, la fecha de prioridad y la independencia de derechos. Es decir, va en apoyo de la protección en el extranjero a través de la patente, pero no la define, ni le da un término mínimo de protección ${ }^{27}$. En este sentido, el ADPIC, no solamente incorpora el Convenio de París a sí mismo ${ }^{28}$, sino que define ampliamente las patentes de invención en los siguientes términos: "las patentes podrán obtenerse por todas las invenciones, sean de productos o de procedimientos, en todos los campos de la tecnología, siempre que sean nuevas, entrañen una actividad inventiva y sean susceptibles de aplicación industrial"29.

Este lenguaje incluyente fue especialmente ideado para que ciertos países no excluyesen de protección productos farmacéuticos o agrícolas ${ }^{30}$. Asimismo, el ADPIC limita y reglamenta los casos en que los países miembros pueden establecer licencias obligatorias, establece los derechos mínimos de los titulares sobre sus patentes, y establece el término mínimo de protección de 20 años contados a partir de la fecha de solicitud de la patente ${ }^{31}$.

Por último, el ADPIC es el primer tratado internacional sobre propiedad intelectual que a nivel global contiene un capítulo de observancia y consecución de derechos. Es decir, que regula cómo deben ser los procedimientos de litigio en caso de infracción. Se incluyen aspectos generales, medidas preliminares, pruebas, daños y perjuicios, así como medidas en la frontera. Si bien estas medidas están dirigidas a autoridades judiciales, el artículo 49 del ADPIC permite que dichos procedimientos sean llevados a cabo ante autoridades administrativas con funciones jurisdiccionales, como es el caso de México. El litigio que nos ocupa ilustra cómo el sistema jurídico mexicano ha asimilado dichas obligaciones internacionales.

\section{ANTECEDENTES DEL LITIGIO}

Para facilitar la lectura, siempre referiré a Takeda como actor, ya que fue quien interpuso la demanda de infracción. El demandado es Representaciones e Investigaciones

\footnotetext{
25 Аввотт et al. (2007) p. 219.

26 WIPO (2018).

27 PIRES (2005) p. 71.

28 Convenio de París para la Protección de la Propiedad Industrial, Estocolmo (28 de septiembre de 1979), art. 2(1).

29 Convenio de París para la Protección de la Propiedad Industrial, Estocolmo (28 de septiembre de 1979), art. 27(1).

30 Mueller (2009) p. 544.

31 ACuerdo sobre los Aspectos de los Derechos de Propiedad Intelectual Relacionados Con EL COMERCIO, Marrakech (15 de abril de 1994), arts. 31, 28 y 33, respectivamente. MARKHAM (2011) p. 124.
} 
Médicas, S.A de C.V. (Rimsa). Lo anterior, independientemente de quien haya interpuesto algún recurso o el propio juicio de Amparo.

Antes de iniciar la acción de infracción o solicitar medidas preliminares, la parte actora Takeda, interpuso un procedimiento contencioso administrativo en contra de una resolución del Instituto Mexicano de la Propiedad Industrial (IMPI) fechada el 25 de enero de 2005, en la que resolvió improcedente modificar la vigencia de la patente objeto de la controversia. Dicho procedimiento se llevó a cabo ante la Sala Especializada en Propiedad Intelectual del Tribunal Federal de Justicia Administrativa (TFJA).

Takeda comenzó sus conceptos de impugnación argumentando que si bien el IMPI había negado modificar la vigencia de la patente, eso no era lo que había solicitado, sino más bien había solicitado la corrección de dicha vigencia ${ }^{32}$. En este sentido, Takeda alegó que originalmente se le concedió fecha de vencimiento de 15 de enero de 2006 debido a que era la fecha en que terminaría la vigencia de la patente en el país cuya fecha de prioridad fue reconocida. Sin embargo, Takeda argumentó que dicha solicitud fue retirada en favor de otra que presentó posteriormente y que generó una patente que vencería en la fecha solicitada, es decir el 9 de enero de 2011. Lo anterior, debido a que la solicitud cuya prioridad fue reconocida nunca se convirtió en patente. Asimismo, argumentó que de acuerdo al artículo décimo segundo transitorio de la Ley de la Propiedad Industrial, se debe tomar como base, la vigencia de la patente otorgada en el país de origen y no en la solicitud, "ya que las solicitudes carecen de vigencia [...]"33.

Lo anterior es cuestionable, ya que si la solicitud original fue retirada en favor de otra, entonces no se trata de la misma invención y tampoco de la misma fecha de prioridad. Además, la diferencia de años en la vigencia de ambas, harían suponer que la reivindicación de la segunda ya no sería novedosa siquiera en su país de origen ${ }^{34}$. Sin embargo, Takeda argumentó que en México se protegió el compuesto reivindicado por ambas solicitudes japonesas, por lo que se trataba del mismo invento y que la fecha de prioridad de la primera era relevante ya que "debe considerarse como la primera solicitud presentada en [...] país [...]" miembro del TCP. Takeda también argumentó la relevancia de la segunda solicitud, pero para determinar la vigencia de la patente en México, ya que argumentaba, era el mismo compuesto que la primera ${ }^{35}$.

Otro agravio de Takeda fue que al emitir su resolución, el IMPI sostuvo que de extender el término de protección estaría violando el artículo 28 constitucional, mismo que fundamenta la protección por "tiempo determinado" de la propiedad intelectual en México. El argumento de Takeda consistió en que solamente los tribunales federales están facultados para interpretar disposiciones constitucionales. Además, razonó que de todos modos, el término de protección establecido por el artículo décimo segundo transitorio de la Ley de la Propiedad Industrial no excedía los 20 años establecidos por el artículo 23 del mismo

\footnotetext{
32 Expediente 14113/05-17-05-9 (2006) p. 4.

33 Expediente 14113/05-17-05-9 (2006) p. 6.

34 A menos que se trate de una solicitud provisional, como la que existe en varios sistemas legales para que la fecha de solicitud original no afecte el término de protección. MigLIORINI (2007) p. 439.

35 Expediente 14113/05-17-05-9 (2006) p. 8.
} 
cuerpo normativo. Finalmente, Takeda alegó que el IMPI transcribió el artículo 4 bis del Convenio de París, pero que no expresó cómo dicho precepto lo llevó a negar la extensión de la patente de invención ${ }^{36}$. En este sentido, manifestó que la independencia establecida por dicho precepto legal solamente es para cuestiones de nulidad y caducidad y que no existe incongruencia entre dicho precepto legal y el artículo décimo segundo transitorio de la Ley de la Propiedad Industrial.

Por su parte, el IMPI argumentó que no estaba facultado por precepto legal alguno para extender el término de protección de la patente. Asimismo, vertió una serie de razonamientos interpretando el artículo 4 bis del Convenio de París, sosteniendo que el régimen de patentes de otro país no puede vincular al régimen nacional, por lo que las modificaciones que se hagan al término de protección en otro país, no deben ser vinculantes en México. Además, sostuvo que el artículo décimo segundo transitorio de la Ley de la Propiedad Industrial únicamente reconoce la fecha de prioridad, y no posteriores modificaciones hechas en el extranjero.

Sin embargo, el TFJA consideró fundados los argumentos presentados por Takeda. Comenzó citando la exposición de motivos del artículo décimo segundo transitorio, manifestando que la intención del legislador fue precisamente atraer al país nuevas tecnologías. Fuera de eso, asumió como propios todos los argumentos vertidos por Takeda, desde el que señalaba que se trataba de una solicitud de corrección de vigencia y no de extensión de la misma, pasando por el argumento que establecía que ambas solicitudes japonesas trataban sobre la misma invención, hasta el argumento que decía que una solicitud que no llegó a ser patente no podría servir "para determinar la caducidad de la patente mexicana [...]"37.

Respecto al artículo 4 bis del Convenio de París, el TFJA sostuvo que: "no tiene aplicación al caso concreto, pues [...] la actora no pretende extender la vigencia de su patente... sino la correcta determinación de la misma" ${ }^{38}$. Sin embargo, el artículo 4 bis del Convenio de París no prohíbe extender la vigencia de una patente, lo que prohíbe es sujetar su vigencia a la patente que originó la fecha de prioridad, cuestión que precisamente hizo el TFJA.

El artículo 4 bis del Convenio de París establece el principio de independencia de derechos de la siguiente manera: "1) Las patentes solicitadas en los diferentes países de la Unión [...] serán independientes de las patentes, obtenidas para la misma invención en los otros países [...] 2) Esta disposición deberá ser entendida de manera absoluta, sobre todo en el sentido de que las patentes solicitadas durante el plazo de prioridad son independientes, tanto desde el punto de vista de las causas de nulidad y caducidad, como desde el punto de vista de la duración normal. [... 5) Las patentes obtenidas con el beneficio de prioridad gozarán...de una duración igual a aquella de la que gozarían si hubiesen sido solicitadas o concedidas sin el beneficio de prioridad" 39 . En este sentido, la contradicción del artículo

36 Expediente 14113/05-17-05-9 (2006) p. 15.

37 Expediente 14113/05-17-05-9 (2006) p. 27.

38 Expediente 14113/05-17-05-9 (2006) p. 29.

39 Convenio de París para la Protección de la Propiedad Industrial, Estocolmo (28 de septiembre de 1979), art 4 bis. 
décimo segundo transitorio de la Ley de la Propiedad Industrial con el artículo 4 bis del Convenio de París es evidente.

Contrario a lo sostenido por el TFJA, el artículo 4 bis del Convenio de París establece el principio de independencia de las patentes de manera "absoluta", desligando totalmente entre sí, a las patentes que se puedan otorgar en los diversos países miembros respecto de causas de nulidad, de caducidad, así como su término de protección. Es decir, la nulidad en el país de origen no significa la nulidad en algún otro país. Tampoco el término de protección otorgado en el país de origen de la fecha de prioridad conlleva a que la patente de otro país deba vencer el mismo día. El quinto párrafo es más específico a la situación del presente litigio, estableciendo que la duración de una patente deberá ser igual al resto de las solicitudes nacionales, es decir aquellas que no hacen valer fecha de prioridad alguna. Es importante notar que, si bien la independencia en cuanto al término de protección se señala en el segundo párrafo junto a la independencia en cuanto a la nulidad y caducidad de las patentes; la independencia de la patente en cuanto su duración, se explica de manera específica en el quinto párrafo. Lo anterior para no dejar lugar a dudas. Por lo tanto, el carácter de absoluto y literal del principio de independencia, lleva indudablemente a concluir la contradicción del artículo décimo segundo transitorio de la Ley de la Propiedad Industrial con el artículo 4 bis del Convenio de París ${ }^{40}$. Cuestión que debió ser sostenida por el TFJA.

El principio de independencia en cuanto al término de protección, ha sido sostenido de manera unánime, tanto por la doctrina ${ }^{41}$, como por la jurisprudencia en diversos países miembros del Convenio de París ${ }^{42}$. La literalidad con la que dicha normativa internacional establece el principio de independencia de la vigencia de las patentes, deja fuera cualquier duda o interpretación en sentido contrario. La sentencia del TFJA no discute el alcance de dicho principio internacional, más bien evade su análisis, asumiendo su inaplicabilidad con el argumento de que no se pedía la ampliación del término de protección. Es decir, no se analiza si el silogismo establecido por el supuesto normativo, encuadra en la situación jurídica planteada. Simplemente se ignora. De haberlo analizado, no hay razonamiento lógico que pudiese sostener la decisión del TFJA.

Aunque no se argumentó en el litigio, consideramos que el artículo décimo segundo transitorio de la Ley de la Propiedad Industrial, además de contradecir el principio de independencia establecido por el Convenio de París, también hizo lo propio con el principio de trato nacional establecido, tanto por el Convenio de París, como por el ADPIC ${ }^{43}$.

Si bien el crear una excepción para proteger estas invenciones, que no eran protegibles antes de la entrada en vigor de la Ley de la Propiedad Industrial es loable, ello no exime al legislador de cumplir con principios establecidos por los diversos tratados internacionales que regulan la materia ${ }^{44}$, especialmente, el principio de trato nacional, o el principio

40 PiRes (2005) p. 74; GOLDSTEIN (2008) p. 353.

41 Véase MAHNe (2012), p. 170; ODDI (1987), p. 860; АввOTT et al. (2007) p. 173.

42 Dicha cuestión también ha sido reconocida, o más bien dada por sentada en la jurisprudencia norteamericana, véase VODA V. CORDIS 476 F.3d 887 (Fed. Cir. 2007), pp. 898-899.

43 CORREA (2007) p. 44.

44 ERSLING Y STROVE (2015) p. 513. 
de independencia, además del término mínimo de protección establecido por el ADPIC, e incorporado al artículo 23 de la Ley de la Propiedad Industrial. Si el legislador ha determinado proteger estas invenciones por medio de patente de invención, entonces las tiene que proteger en los términos establecidos, tanto por los tratados internacionales, como por la propia legislación nacional. Lo anterior, impide sujetar su término de protección, al otorgado en el país de origen. Haber hecho lo contrario, ha provocado un sinnúmero de litigios e incertidumbre, incluyendo lo ocurrido en la presente controversia.

Es decir, si un país miembro otorga determinado derecho o término de protección de cualquier figura jurídica de propiedad industrial a sus nacionales, ese mismo derecho o término tendrá que ser otorgado a los nacionales de los demás países miembros del Convenio ${ }^{45}$. De manera que, si a los inventores mexicanos que presentaron su solicitud de patente en la misma fecha que lo hizo Takeda en México, les aplicaron el artículo 23 de la Ley de la Propiedad Industrial, recibiendo así un término de protección de 20 años contados a partir de esa fecha, y a Takeda no se le otorgó el mismo término, estamos frente una violación al principio de trato nacional. Lo anterior, no obstante, cualquier excepción o beneficio que haya recibido el titular extranjero del artículo décimo segundo transitorio de la Ley de la Propiedad Industrial.

Todo lo anterior plantea una fuerte problemática en el sistema jurídico mexicano ya que de acuerdo al artículo 133 Constitucional, los tratados internacionales son jerárquicamente superiores a las leyes ordinarias ${ }^{46}$. De manera que, si un precepto legal o una normativa contradicen un tratado internacional, por cuestión de legalidad tendría que prevalecer lo establecido por el tratado internacional ${ }^{47}$.

\section{DECLARACIÓN DE INFRACCIÓN ANTE IMPI}

Lo que a continuación se expone, muestra cómo se ha incorporado al sistema jurídico mexicano, el tercer apartado del ADPIC sobre observancia de los derechos de propiedad intelectual ${ }^{48}$.

Resulta conveniente puntualizar que las resoluciones emitidas por el IMPI pueden recurrirse opcionalmente ante el superior jerárquico en la propia sede, o bien directamente ante el TFJA quien podrá declarar la nulidad de la resolución recurrida y ordenar al IMPI dicte una nueva resolución en los términos establecidos por el propio tribunal. Tal como ocurrió en el apartado anterior. La resolución del TFJA puede ser combatida a través del juicio de Amparo Directo.

Lo anterior, no parece tan complejo, pero es sorprendente saber que después de haber agotado el Amparo, aunque la parte actora haya ganado, aún no tendría a su favor

\footnotetext{
45 PIRES (2005) p. 72.

46 Pleno de la Suprema Corte de Justicia de la Nación, Tesis: P. LXXVII/99, Semanario Judicial de la Federación y su Gaceta, Novena Época, tomo X, Noviembre de 1999, p. 46.

47 Segunda Sala de la Suprema Corte de Justicia de la Nación. Tesis: IV.2o.A.76 K (10a.), Gaceta del Semanario Judicial de la Federación, Libro 12, Noviembre de 2014, Tomo IV, p. 2918.

48 Acuerdo sobre los Aspectos de los Derechos de Propiedad Intelectual Relacionados Con EL COMERCIO, Marrakech (15 de abril de 1994), arts. 41 a 60.
} 
una condena de daños y perjuicios, ya que el IMPI no está facultado para emitirla. Ahora precisaría iniciar un juicio ordinario, ante un juzgado civil, con su respectiva apelación, además del Amparo en contra de la misma. Sin embargo, el litigio en análisis no llegó hasta la acción de daños y perjuicios. Cabe mencionar que una resolución firme del IMPI, es presupuesto para iniciar el juicio ordinario civil sobre daños y perjuicios. Todo lo anterior, promete demorar hasta una década, violando con ello el principio de eficacia en los procedimientos de consecución de derechos establecido por el primer párrafo del artículo 41 del ADPIC. Esto vuelve más complicado de lo que ya supone un litigio de patente ${ }^{49}$. Ahora veamos el litigio de infracción ante el IMPI.

El 15 de junio de 2006, el representante legal de Takeda, presentó una solicitud de medidas provisionales en contra de Rimsa. Dicha solicitud fue basada en el artículo 199 bis de la Ley de la Propiedad Industrial. Precepto normativo que, fue emitido por el Congreso Federal para incorporar el artículo 50 del ADPIC al sistema jurídico mexicano, estableciendo con ello las medidas preliminares sin audiencia de parte contraria.

Sin embargo, dicha solicitud no fue admitida a trámite, debido a que el IMPI determinó que la vigencia de la patente base de la acción se encontraba en litigio ${ }^{50}$.

Y es que el 9 de febrero de 2006, el IMPI había publicado en la Gaceta de la Propiedad Industrial que, la patente se encontraba vigente por una orden judicial ya que su término de protección se hallaba en litigio. En contra de esta publicación, así como de las resoluciones que previamente derivaron en la extensión de término de la patente, Rimsa promovió varios juicios de Amparo, buscando revertir dicha extensión. Sin embargo, no tuvo éxito en ninguno.

Consecuentemente, el 26 de julio de 2006, el IMPI emitió dos oficios, en el primero tuvo por presentada la solicitud de Takeda sobre medidas provisionales, en tanto que, en el segundo emitió las medidas preliminares solicitadas, consistentes en suspender la fabricación, venta, ofrecimiento en venta y distribución del medicamento Diaberil, cuyo componente activo era Pioglitazona. También se ordenó retirar de circulación o distribución el medicamento en cuestión, así como su aseguramiento, ordenando además a la demandada abstenerse de fabricar y comercializar cualquier producto que contuviese el ingrediente activo en cuestión.

El artículo 199 bis 1 de la Ley de la Propiedad Industrial establece los requisitos que el actor debe demostrar a fin de lograr la emisión de la medida preliminar. El primero de ellos es la titularidad del derecho. Para demostrarlo, el actor presentó copia certificada del título original de la patente número 181354 , aquél cuya fecha original de vencimiento era 15 de enero de 2006. Sin embargo, no presentó además, el oficio emitido el 20 de julio de 2006 por el IMPI mediante el cual implementó la sentencia del TFJA referida en anteriores líneas, teniendo por extendida la vigencia de la patente hasta el 9 de enero de 2011. Resulta cuestionable que dicho oficio se haya emitido después de la fecha en que la actora presentó su escrito inicial solicitando las medidas preliminares, es decir el 15 de junio de 2006. Lo anterior debido a que, al final de cuentas, al emitir la medida preliminar, el IMPI solamen-

49 ANDREWS (2011) p. 226

50 TAKEDA V. RIMSA (2013) p. 3. 
te fundamentó en este oficio la titularidad del derecho, que no existía cuando se solicitaron dichas medidas. Se aplicó retroactivamente.

De acuerdo a la resolución, la actora demostró todos los elementos establecidos por el artículo 199 bis 1 de la Ley de la Propiedad Industrial, ya que además de probar la titularidad del derecho, evidenció la violación actual e inminente a sus derechos, así como el posible daño irreparable, además de proporcionar información necesaria para la identificación de los productos infractores y el lugar en el que se estaba cometiendo la infracción. Además, el IMPI dio cuenta de una fianza por la cantidad de veinte millones de pesos, presentada por la actora a fin de garantizar posibles daños y perjuicios que la medida pudiese ocasionar a la demandada.

De conformidad con el segundo párrafo del artículo 199 bis 1 de la Ley de la Propiedad Industrial, la persona en cuya contra se hayan dictado medidas preliminares, puede obtener su levantamiento mediante una contrafianza suficiente para responder de daños y perjuicios. Fundamentándose en lo anterior, la parte demandada presentó una póliza de contrafianza por veinticuatro millones de pesos, a fin de obtener dicho beneficio. El 13 de septiembre de 2006, el IMPI aceptó la contrafianza y ordenó retirar dichas medidas.

Si bien la parte actora intentó impedir lo anterior mediante diverso juicio de Amparo, el mismo fue desechado, por lo que las medidas preliminares fueron finalmente retiradas. Sin embargo, debido a que, la actora prevaleció en la acción de infracción principal, el IMPI puso a su disposición, la contrafianza presentada por la demandada, lo que ilustra el riesgo que enfrentan los demandados que evaden las medidas preliminares mediante esta disposición normativa.

Hasta aquí, el tema de las medidas preliminares sin audiencia de la parte contraria. Lo anterior ilustra cómo funciona el artículo 50 del ADPIC en el sistema jurídico mexicano.

Ahora veamos la acción de infracción, todo dentro del mismo expediente. El 23 de agosto de 2006, el representante legal de Takeda presentó un escrito por medio del cual demandó la declaración administrativa de infracción, basada en los supuestos establecidos por las fracciones XI, XII y XXVII del artículo 213 de la Ley de la Propiedad Industrial. La parte demandada dio contestación a la acción planteada el 19 de diciembre de 2006. Después de desahogadas las pruebas y de agotadas las etapas del procedimiento, el 27 de febrero de 2009 el IMPI emitió una resolución en la que declaró la infracción administrativa de cada uno de los supuestos solicitados.

Se comenzó con el estudio de las excepciones interpuestas por Rimsa. Una de ellas, consistió en que de acuerdo a su título original, la patente base de la acción venció el 15 de enero de 2006. Por lo tanto, la actora carecía de acción y derecho para demandar su infracción puesto que la misma se encontraba caduca. Además, Rimsa argumentó la ausencia de algún precepto legal que facultara al IMPI a extender la vigencia de una patente. En este sentido, el IMPI se limitó a declarar improcedente la excepción, sosteniendo que mediante oficio emitido el 20 de julio de 2006 acató lo ordenado por el TFJA, modificando así la vigencia de la patente al 9 de enero de 2011. El IMPI no pasó por alto el hecho de que la resolución de dicho tribunal provenía precisamente de un juicio de nulidad interpuesto por Takeda en contra de la resolución en la que el propio IMPI originalmente se había negado a extender la vigencia de la patente en cuestión. 
Posteriormente, el IMPI se avocó a la enumeración y valoración de las pruebas presentadas. Describiré brevemente las más importantes.

La primera prueba fue la copia certificada del título de patente base de la acción, a la que el IMPI dio valor probatorio pleno para acreditar la titularidad de los derechos de propiedad industrial de la actora. Lo anterior, no obstante a que de acuerdo con dicho título, la patente había vencido el 15 de enero de 2006. La actora también presentó como prueba una copia certificada de la portada y de la página 53 de la Gaceta del IMPI publicada el 9 de febrero de 2006. Si bien el IMPI dio valor probatorio pleno a dicha probanza, no estableció lo que se pretendía demostrar con la misma.

La actora además, presentó una documental privada que hizo consistir en una muestra del producto comercializado por la demandada llamado Diaberil. Asimismo, presentó una documental pública consistente en una fe de hechos levantada el 12 de junio de 2006 por una corredora pública quien se apersonó en una farmacia determinada, dando fe de que allí se ofrecía a la venta un medicamento llamado Diaberil, que contenía Pioglitazona. Para constatar lo anterior, la corredora pública solicitó al encargado del establecimiento el medicamento en todas sus presentaciones, dicha persona le aseguró que había dos presentaciones, pero solamente tenían una de ellas. Al serle entregado en el mostrador, procedió a la compra del mismo solicitando al momento su factura. Tanto el medicamento como la factura fueron agregados a la fe de hechos, el medicamento mediante una bolsa plástica sellada a la que se le colocó una etiqueta indicando que formaba parte del acta levantada con motivo de la fe de hechos.

La actora también presentó como prueba, la confesional, que, argumentó, hizo la demandada en el propio empaque del producto comercializado como Diaberil, misma que hizo consistir en la leyenda del empaque que establecía que el producto había sido "hecho en México" por la demandada Rimsa ${ }^{51}$. Otra prueba importante fue la derivada de la visita de inspección realizada por el IMPI el 27 de marzo de 2006 a un domicilio identificado en la propia diligencia como propiedad de la demandada, allí se fabricaban, almacenaban y acondicionaban productos farmacéuticos, entre ellos Diaberil, lo que se hizo constar en el acta respectiva.

La actora también presentó una prueba consistente en otra visita de inspección realizada el 5 de julio de 2006 por un corredor público para hacer constar que en un hotel de la Ciudad de México se llevó a cabo el lanzamiento comercial del producto Diaberil por parte de la demandada. Haciendo constar además, partes del discurso hecho por el director general de la empresa demandada, quien de acuerdo al acta dijo entre otras cosas lo siguiente: "la vigencia de la patente ya venció y Takeda solicitó una ampliación de la misma, situación que no está considerada en la ley [...] el producto es seguro porque cumple con el principio activo [...] se cuenta con un registro sanitario [...] Rimsa [...] tiene los argumentos legales para defenderse [... $]^{\prime 52}$. Dicho fedatario también hizo constar la recepción de un folleto con la descripción del medicamento, mismo que anexó al acta, además de dos muestras médicas del producto objeto de la controversia. Cabe mencionar que la actora presentó

51 TAKEDA V. RIMSA (2013) p. 45.

52 TAKEDA V. RIMSA (2013) p. 53. 
otra visita de inspección igual a la anterior, pero esta vez levantada por un notario público en Guadalajara, en otro hotel, en otra presentación del medicamento llevada a cabo el 4 de julio de 2006, y protocolizada un día después.

Además, la parte actora presentó como prueba la visita de inspección realizada el 27 de julio de 2007 por personal del IMPI a un domicilio señalado por la actora como el lugar en el que la demandada Rimsa fabricaba el producto infractor. En dicho lugar, el inspector hizo constar varios puntos fácticos formulados por el propio IMPI mediante oficio girado previamente, entre ellos la fabricación del medicamento objeto de la controversia. Además, se hicieron constar otros puntos respecto a la identidad del establecimiento, fabricación, y almacenamiento de productos infractores, para finalmente asegurar mercancía infractora.

La primera causa de la acción interpuesta fue la establecida por la fracción XI del artículo 213 de la Ley de la Propiedad Industrial, mismo que establece como infracción: "fabricar o elaborar productos amparados por una patente o por un registro de modelo de utilidad o diseño industrial, sin consentimiento de su titular o sin la licencia respectiva”. A fin de configurar esta causa de la acción, en su resolución, el IMPI estableció dos elementos hipotéticos a demostrar: el primero de ellos, la existencia de una patente, propiedad de una persona, en tanto que el segundo elemento consistía en demostrar la fabricación o elaboración de productos amparados por dicha patente, sin contar con el consentimiento o licencia del titular de la misma ${ }^{53}$.

Y aquí es en donde la cuestión parece no embonar del todo bien, ya que, para demostrar el primer elemento, es decir la existencia de un derecho de patente valido, el IMPI solamente consideró el título de patente, sin razonar o dar mayor análisis sobre la extensión de su término de protección. Es decir, solamente mencionó un título cuyo vencimiento fue el 15 de enero de 2006, cinco meses antes de que la actora presentara su demanda de infracción; omitiendo así, hacer mención del oficio emitido por el propio IMPI el 20 de julio de 2006 en donde acatando lo ordenado por el TFJA extendió la vigencia de la patente al 9 de enero de 2011. Asimismo, el IMPI tampoco mencionó publicación alguna en la Gaceta sobre la extensión del término de protección. Lo anterior es de suma importancia, ya que si bien del expediente se puede inferir la vigencia derivado de la extensión de la misma, en una resolución fundada y motivada ${ }^{54}$, esta cuestión se tuvo que haber establecido claramente.

El segundo elemento de la causa de la acción, referente a la fabricación o elaboración del producto patentado sin autorización o licencia del titular de la patente, fue acreditado por el IMPI únicamente mediante la visita de inspección realizada por personal del propio IMPI el 27 de julio de 2006 al domicilio de la demandada Rimsa.

La doctrina ha establecido que lo más difícil al momento de demostrar una infracción de patente, es si el producto o proceso infractor infringió las reivindicaciones de la patente base de la acción ${ }^{55}$. Es decir, se compara el producto infractor con las reivindicaciones del título de patente original. Cuestión que no ocurrió aquí, ya que la demandada abierta-

53 TAKEDA V. RIMSA (2013) p. 107.

54 ACuerdo sobre los Aspectos de los Derechos de Propiedad Intelectual Relacionados Con EL COMERCiO, Marrakech (15 de abril de 1994), art 41(3), establece que las resoluciones que declaran la infracción deben ser "razonadas".

55 MCJOHN (2003) p. 173. 
mente fabricaba y comercializaba un producto que invadía la patente de la actora, con la expectativa que estaría en el dominio público.

Como segunda causa de la acción, la actora interpuso la infracción administrativa establecida en la fracción XII del artículo 213 de la Ley de la Propiedad Industrial, consistente en: "[...] ofrecer en venta o poner en circulación productos amparados por una patente [...] a sabiendas de que fueron fabricados o elaborados sin consentimiento del titular [...]".

El primer elemento, la titularidad de una patente válida, se tuvo por demostrado con el análisis de la primera causa de la acción. El IMPI tuvo por demostrado el segundo elemento, es decir el ofrecimiento del producto al público, debido a que la propia demandada Rimsa fabricaba el producto denominado Diaberil, que contenía el compuesto protegido por la patente base de la acción, "sin que se acredite su autorización o licencia respectiva, para fabricar o elaborar el citado producto" 56 . Sin embargo, en dicho razonamiento no se mencionó prueba alguna que demostrara dicha fabricación. Tampoco se mencionó por qué la fabricación implicaba el ofrecimiento al público, supuesto jurídico en análisis.

Ya en el estudio del tercer elemento, es cuando la resolución da cuenta del segundo, es decir aquí el IMPI analizó el ofrecimiento a la venta del producto infractor sin autorización, además del conocimiento de ello, que es propiamente el tercer elemento para configurar la infracción. A fin de demostrar lo anterior, el IMPI se basó en dos diligencias notariales sobre fe de hechos, en donde se hizo constar la presentación del producto Diaberil por parte de Rimsa. Una presentación se llevó a cabo en un hotel de Guadalajara y la otra en un hotel del Distrito Federal. Como había descrito en anteriores líneas, en esta última el fedatario hizo constar que el Director General de Rimsa, en uso de la palabra había manifestado que la patente objeto de la presente controversia ya había vencido y que la actora había solicitado la ampliación de su término de protección. Con ello, el IMPI consideró que Rimsa, "ya tenía conocimiento de la existencia de la patente indicada y que es base de la acción, quedando acreditado en el presente procedimiento el elemento 'a sabiendas', actualizándose en la especie la causal de infracción en estudio" 57.

La última causa de la acción interpuesta por el actor, contenida en la residual fracción XVII del artículo 213 de la Ley de la Propiedad Industrial, establece como infracción: "las demás violaciones de las disposiciones de esta Ley que no constituyan delitos [...]”. Esta fracción se relacionó con los derechos exclusivos otorgados a los titulares de las patentes por la fracción I del artículo 25 de la misma normativa, consistentes en el "derecho de impedir a otras personas que fabriquen, usen, vendan, ofrezcan a la venta o importen el producto patentado, sin su consentimiento [...]”. El IMPI declaró esta infracción debido a la fabricación por parte de la demandada del producto denominado Diaberil, conteniendo la substancia protegida por la patente base de la acción, sin contar con la autorización para ello.

Finalmente, en la parte resolutiva, el IMPI condenó a la demandada Rimsa a pagar una multa por la cantidad de veinte mil días de salario mínimo ${ }^{58}$. Asimismo, ordenó a la demandada "se abstenga de fabricar o elaborar, así como ofrecer en venta o poner en cir-

56 TAKEDA V. RIMSA (2013) p. 108.

57 TAKEDA V. RIMSA (2013) p. 109.

58 Alrededor de ochenta mil dólares americanos, al tipo de cambio de 20 pesos mexicanos por dólar. 
culación productos que invadan [...] la patente 181354 [...]"59. En este sentido, el IMPI determinó hacer definitivas las medidas preliminares impuestas a la demandada, ordenando poner a disposición de la actora la fianza que presentó al solicitar dichas medidas. Además, ordenó poner a disposición de la parte actora, la contrafianza presentada por la demandada a fin de levantar las medidas preliminares, contrafianza que ascendió a la cantidad de veinticuatro millones de pesos ${ }^{60}$.

\section{JUICIO DE NULIDAD TFJA}

En contra de la resolución de infracción del IMPI, la demandada Rimsa interpuso juicio de nulidad ante el TFJA. Podría resumir dichos motivos de impugnación de la siguiente manera, primeramente se argumentaba que no existía en la legislación precepto legal que autorizara la ampliación del término de protección de una patente; además la demandada argumentaba, que no había sido oída en dicho procedimiento ya que no formó parte del mismo, lo que violaba su garantía de audiencia ${ }^{61}$. Finalmente, argumentó que dicha extensión en el término de protección no le era oponible dado que no había sido publicada en la Gaceta de la Propiedad Intelectual. Por lo tanto, no se actualizaron las infracciones a las que fue condenada.

Nuevamente, el TFJA resolvió en contra de la demandada, desestimando sus argumentos ya que los consideró cosa juzgada. Para el estudio de los mismos, el TFJA comenzó enumerando diversos juicios de Amparo interpuestos por Rimsa en contra de la extensión del término de protección de la patente en los que argumentó que no fue escuchada, ya que no fue parte en ninguno de los procedimientos que derivaron en la extensión de la patente, lo que violaba su garantía de audiencia. Sin embargo, esos Amparos fueron desechados debido a que los juzgadores no encontraron vicios propios de los procedimientos impugnados, sino afectaciones para Rimsa por "vía de consecuencia"62.

Por otra parte, el TFJA sostuvo que la legalidad del oficio mediante el cual el IMPI cumplimentó lo ordenado extendiendo el término de protección de la patente había sido confirmada anteriormente, en el propio juicio contencioso en el que el TFJA ordenó al IMPI extender dicho término, considerando así que se trataba de cosa juzgada. En este sentido, estableció que: "se había realizado un pronunciamiento sobre un elemento vinculante para las partes $[\ldots]$ considerar lo contrario implicaría una violación a los principios de certeza y seguridad jurídicas" 63 .

Así, el TFJA sostuvo que, debido a que ya había quedado firme que la extensión de la patente que prolongaba su vigencia hasta el 9 de enero de 2011, resultaba inadmisible que la demandada Rimsa "pretendiera exceptuarse de las infracciones declaradas bajo el argumento de que la patente [...] había perdido su vigencia [...]"64. Además, sostuvo que

59 TAKEDA V. RIMSA (2013) p. 113.

60 Alrededor de un millón doscientos mil dólares americanos, al tipo de cambio de 20 pesos mexicanos por dólar.

61 Amparo Directo 245/2014 (2014) p. 28.

62 Amparo Directo 245/2014 (2014) p. 33.

63 Amparo Directo 245/2014 (2014) p. 34.

64 Amparo Directo 245/2014 (2014) p. 34. 
era falso que la extensión no hubiese sido publicada, refiriendo a la publicación del 31 de agosto de 2006, así como la publicación de marzo de 2007, sosteniendo además que "resultaba evidente que la modificación había surtido plenos efectos contra terceros" ${ }^{65}$. Ello, aunque ambas publicaciones fueron posteriores al inicio del procedimiento de infracción. Para ahondar en este argumento, el TFJA sostuvo que las resoluciones de los Amparos que Rimsa promovió en contra de la extensión tornaban inadmisibles los argumentos de Rimsa en el sentido que "pretendiera el desconocimiento de dicha publicación [...]"66. Ello aunque el argumento no se centrara en el conocimiento o la falta del mismo, sino en la expectativa de derecho de que aquello pasaría al dominio público en una fecha determinada, la legalidad de la extensión, y el elemento formal de la publicación en la Gaceta a fin de que dicha extensión fuese oponible a terceros, aquellos que no fueron parte en los procedimientos de extensión.

Si bien el TFJA reconoció que Rimsa no pudo intervenir en los procedimientos de extensión de la vigencia de la patente, "al no haber sido admitida su intervención [...] no correspondía a dicha Sala dilucidar la legalidad de aquella determinación” ${ }^{67}$. Además, sostuvo que la falta de interés jurídico habría sido la principal razón para que se sobreseyeran los juicios de amparo promovidos para combatir la extensión de la patente.

Lo anterior plantea un punto importante, ya que primero no se permitió a la demandada intervenir en estos procedimientos por falta de interés jurídico y después aquello era cosa juzgada. Ello sin importar la expectativa de derecho que significa el vencimiento de una patente, cuestión que la hace de dominio público, creando así una verdadera expectativa de derecho, sobre todo cuando se es un laboratorio que planea fabricar dicho medicamento, una vez que este pase al dominio público. Incluso con inversión monetaria y tramitación de permisos ante autoridades sanitarias. Si eso no fue considerado interés jurídico se debió a un excesivo y cegador formalismo por parte de aquellos tribunales.

Finalmente, el TFJA estableció, que, si bien la actora contaba con interés jurídico para impugnar la extensión de la vigencia de la patente, dicho agravio sería ineficaz ya que esa modificación de la vigencia había quedado firme mediante un fallo con efectos de cosa juzgada.

Respecto de los agravios relativos a la legalidad de la declaración de infracción, el TFJA sostuvo que los mismos eran infundados ya que el IMPI había fundamentado correctamente su declaración en preceptos legales interpretados correctamente. Asimismo, sostuvo que el IMPI había valorado correctamente las pruebas presentadas para demostrar las infracciones contenidas en las fracciones XI, XII y XXVII del artículo 213 de la Ley de la Propiedad Industrial.

Un último agravio se refería a que no podría dictarse la resolución de infracción debido a que Rimsa había iniciado ante el IMPI un procedimiento de nulidad en contra de la patente base de la acción. Sin embargo, el TFJA tuvo por no presentada dicha demanda ${ }^{68}$.

65 Amparo Directo 245/2014 (2014) p. 35.

66 Amparo Directo 245/2014 (2014) p. 35.

67 Amparo Directo 245/2014 (2014) p. 36.

68 Amparo Directo 245/2014 (2014) p. 42. 
Con esa información, el TFJA desechó el agravio sosteniendo que la resolución del IMPI negando la nulidad de la patente tenía la presunción de legalidad.

\section{AMPARO DIRECTO 245/2014.}

En el sistema jurídico mexicano, el juicio de Amparo procede entre otras causas, en contra de la violación de alguna garantía individual. La mayoría de las veces en este tipo de procedimientos, la garantía constitucional infringida es la exacta aplicación del derecho contenida en los artículos 14 y 16 constitucionales ${ }^{69}$. Si bien esto fue criticado históricamente ya que convertía un recurso de casación en una acción constitucional que llenaría de casos los tribunales constitucionales ${ }^{70}$, actualmente la amplitud del juicio de Amparo es un sello característico del sistema jurídico mexicano ${ }^{71}$. En contra de la resolución del TFJA que antecede, Rimsa interpuso un Amparo Directo, con los siguientes argumentos de inconformidad relacionados con la exacta aplicación del derecho principalmente. Además, algunos argumentos se relacionaban con la garantía de audiencia y la garantía de irretroactividad.

Tanto el primero como el segundo concepto de violación, referían de nueva cuenta a la extensión del término de protección de la patente base de la acción. Los mismos eran parecidos a los motivos de inconformidad que sobre el tema fueron presentados al TFJA, agregando además que la existencia del oficio por medio del cual el IMPI extendió el término de protección de la patente no impedía analizar los argumentos presentados. En este sentido Rimsa señaló que el TFJA se limitó a argumentar que dicha ampliación era cosa juzgada. También señaló que la publicación realizada en la Gaceta sobre la extensión fue hecha posteriormente a la solicitud de infracción, es decir que la conducta base de la acción se había llevado a cabo antes de la publicación en la Gaceta, anteriormente a que la modificación del término surtiera efectos frente a terceros. Además, argumentó que la figura de cosa juzgada utilizada por el TFJA no le era oponible ya que no tuvo intervención en el juicio de nulidad que extendió el término de protección de la patente. Aunado a lo anterior, argumentó que el oficio por medio del cual el IMPI dio cumplimiento a lo ordenado por el TFJA, extendiendo el término de protección de la patente, fue posterior a la presentación de la demanda. Por otra parte, alegó que al habérsele negado participación por falta de interés jurídico en los procedimientos de extensión de la patente debido a que las medidas provisionales fueron aplicadas posteriormente a dicha extensión, eso le hacía que estuviese legitimada para combatir la extensión en el procedimiento de infracción ${ }^{72}$.

En estos argumentos podemos ver violaciones a la garantía de audiencia, ya que no se le permitió participar en los procedimientos de extensión del término de protección de la patente base de la acción, además de violaciones a la garantía constitucional que protege al gobernado a que le apliquen una ley o un acto administrativo de manera retroactiva.

69 En este caso específico, en la doctrina suele llamársele Amparo Casación, por su similitud al recurso de casación de origen francés. FIX-ZAMUdio y VALENCIA (2009) p. 924.

70 RABASA (1955) pp. 75 y 103.

71 BURGOA (2009) p. 145.

72 Amparo Directo 245/2014 (2014) p. 47-51. 
En su tercer concepto de violación, Rimsa refería que la misma conducta no podría configurar al mismo tiempo tres tipos legales, como las fracciones XI, XII y XXVII del artículo 213 de la Ley de la Propiedad Industrial. Además, alegaba que no se actualizaban los supuestos de las fracciones XI y XII de dicho precepto legal, ya que las mismas establecían como presupuesto que el presunto infractor tuviera el conocimiento de la infracción, cuestión que no se perfeccionó. En el caso de la fracción XI debido a que habla de un derecho de patente que en este caso ya había vencido, en tanto que en el caso de la fracción XII la frase "[...] a sabiendas [...]" establecida por dicho precepto legal establecía también dicho conocimiento.

El cuarto argumento se relacionó con el concepto de impugnación alegado ante el TFJA referente a que el procedimiento de infracción no debía resolverse hasta en tanto quedara firme la resolución de nulidad interpuesta en contra de la patente base de la acción. Esto debido a que todavía se podría promover un Amparo. En este sentido, Rimsa argumentó que el TFJA incorrectamente sostuvo la presunción de legalidad de la declaración de nulidad de la patente. A fin de demostrar lo anterior, Rimsa presentó como prueba superviniente una sentencia dictada por el propio TFJA, con motivo de diverso Amparo resuelto con posterioridad en el que se le ordenó pronunciarse sobre la resolución del IMPI que negó la nulidad de la patente. Dicha sentencia fue presentada a fin de demostrar que, a diferencia de lo sostenido por el TFJA, la sentencia de nulidad de la patente no había quedado firme $\mathrm{e}^{73}$.

El Tribunal solamente analizó el concepto de violación consistente en que la nulidad de la patente no había quedado firme. Para llegar a esta determinación citó casi literalmente el artículo 189 de la Ley de Amparo, mismo que establece que debe estudiarse primordialmente el fondo de las cosas por encima de la forma o procedimiento, "a menos que [...] invertir el orden redunde en un mayor beneficio para el quejoso" 74 . Sin embargo, sin explicar en qué beneficiaría al quejoso, el Tribunal estableció que se estaba frente a la última hipótesis normativa, y por esa razón sostuvo que estudiaría primero el tercer concepto de violación. Aunque realmente no era el tercero sino el cuarto. Además, por los efectos que tuvo el Amparo, aunque lo haya ganado el quejoso, no le veo gran beneficio puesto que se dejaron fuera los otros conceptos de violación, que de haberlos ganado le habrían beneficiado en definitiva.

Así, el Tribunal Colegiado estableció que dicho concepto de violación se centraba en "la ilegalidad de la determinación de la responsable de no ordenar la suspensión del procedimiento [...] aun cuando se encuentra en trámite un juicio diverso en el que se alega la nulidad de la patente controvertida [...]"75. Acto seguido, citó varios preceptos legales tanto de la Ley de la Propiedad Industrial, como del Código Federal de Procedimientos Civiles de aplicación supletoria de aquella, entre ellos su artículo 366, mismo que establece que se suspenderá el procedimiento "cuando no pueda pronunciarse la decisión, sino hasta

73 Amparo Directo 245/2014 (2014) p. 58.

74 Amparo Directo 245/2014 (2014) p. 60, citando el precepto legal.

75 Amparo Directo 245/2014 (2014) pp. 60 y 61. 
que se pronuncie una resolución en otro negocio [...]"76. Después sostuvo que dicha figura jurídica tiene el objetivo de evitar resoluciones contradictorias tratándose de procedimientos sobre temas conexos. Asimismo, sostuvo que si bien el TFJA negó suspender el procedimiento debido a que el IMPI ya había negado la nulidad de la patente en cuestión, y que el propio TFJA había tenido por no interpuesta la demanda de nulidad en contra de la resolución del IMPI, el Tribunal Colegiado determinó que dicha resolución fue ilegal y por lo tanto violatoria de derechos fundamentales, ya que lo anterior era insuficiente para negar la suspensión ya que no había transcurrido el plazo para interponer el Amparo.

Finalmente, el Tribunal Colegiado dejó insubsistente la resolución reclamada, ordenando al TFJA dictar una nueva resolución en la que determinara si la resolución que desechó la demanda de nulidad de la resolución del IMPI, que negó la nulidad de la patente, había quedado firme, cuestión que obviamente iría en el sentido negativo. El propio Colegiado había sostenido que así fue. Además ordenó al TFJA determinar "las consecuencia [sic] que ello tiene en el procedimiento de infracción [...]"77. Es decir, básicamente lo que hizo fue reenviar el caso al TFJA para que determinara libremente la consecuencia de la sentencia que declaró la nulidad de la resolución que negó la nulidad de la patente.

En la cumplimentación de lo anterior, el TFJA estableció que no se podría analizar nuevamente la legalidad de la resolución que extendió el término de protección de la patente. Además, sostuvo que el IMPI valoró correctamente las pruebas y configuró de manera fundada y motivada la hipótesis normativa. Consecuentemente, declaró que los argumentos de Rimsa en contra de dicha resolución fueron insuficientes ${ }^{78}$. Finalmente, declaró la nulidad de la resolución impugnada; sin embargo, el único efecto de dicha nulidad fue que se suspendiera el procedimiento de infracción, "hasta en tanto sea resuelto el procedimiento de declaración administrativa de nulidad en que se ventila la patente [...] de manera definitiva" 79 .

El Tribunal Colegiado estuvo de acuerdo con la anterior cumplimentación por parte del TFJA. De conformidad con los artículos 201 fracción I y 202 de la Ley de Amparo, el recurso de inconformidad procede en contra del auto que declara cumplida la sentencia de Amparo. En el caso específico, Rimsa promovió dicho recurso, mismo que fue resuelto por la Segunda Sala de la Suprema Corte de Justicia de la Nación resolvió el 12 de agosto de 2015.

El argumento de Rimsa, básicamente consistió en que el TFJA no debió hacer estudio alguno sobre el fondo de la resolución de infracción del IMPI, ya que se trataba de una nulidad lisa y llana. En sus propias palabras, el efecto de la declaración de nulidad del TFJA debió ser que "ni siquiera existiría resolución" 80 de infracción. Bajo este razonamiento, el IMPI tendría que dictar nuevamente dicha resolución de infracción y no dejarla en suspenso hasta que se resolviera en definitiva la nulidad de la patente.

\footnotetext{
76 Amparo Directo 245/2014 (2014) p. 72.

77 Amparo Directo 245/2014 (2014) p. 76.

78 Recurso de Inconformidad 608/2015 (2015) p. 11.

79 Recurso de Inconformidad 608/2015 (2015) p. 13

80 Recurso de Inconformidad 608/2015 (2015) p. 14.
} 
La Segunda Sala declaró ineficaces los motivos de agravio presentados por Rimsa, sosteniendo que, al cumplimentar la resolución de Amparo, el TFJA anuló la resolución del IMPI de acuerdo a las directrices dictadas por el Colegiado. Las mismas consistían en determinar si quedó firme la resolución de nulidad de la patente y posteriormente establecer cómo lo anterior incidiría en el procedimiento de declaración de infracción. Así, la Suprema Corte sostuvo que:

"[...] lejos de constreñir a la autoridad administrativa responsable [...] se le dejó en libertad de establecer [...] la condición en que quedaría el procedimiento de declaración administrativa de infracción [...]"81.

\section{CONCLUSIONES}

El anterior litigio muestra al menos dos problemas. El primero es una mala técnica legislativa que, al emitir el artículo décimo segundo transitorio de la Ley de la Propiedad Industrial, ignoró o rechazó los principios básicos que sobre las patentes han establecido tanto el Convenio de París como el ADPIC. Sobre todo, los principios de trato nacional e independencia de las patentes. El segundo problema, es la interpretación tan liberal y activista que los jueces han tenido de dicho precepto legal.

Lo anterior no es un caso aislado, sino que ha sido un problema generalizado. Resuelto, no por acción legislativa o judicial, sino por el paso del tiempo. Para ejemplificar lo anterior, una nota periodística publicada, el 12 de Septiembre de 2010, dio cuenta de lo generalizado del problema ${ }^{82}$. La misma hace referencia al litigio que nos ocupa y sugiere que el problema analizado es algo común: "[...] el problema dicen los nacionales productores de genéricos, es que más de la cuarta parte de las patentes de fármacos publicadas hoy en la gaceta son por mandato judicial, es decir, que un juez ordenó al IMPI protegerlas pese a que el mismo IMPI había rechazado hacerlo..."83.

En relación a lo anterior, el Senado de la República emitió un punto de acuerdo en donde se exhortó al TFJA a circunscribirse a la ley y no extender el término de protección de patentes basándose en el artículo décimo segundo transitorio de la Ley de la Propiedad Industrial. Es decir, en su interpretación de dicho precepto normativo, los Senadores consideraron que no existe fundamento jurídico para extender o ajustar la duración de las patentes ${ }^{84}$.

Además, resulta desafortunado y excesivamente formalista el criterio que dejo a la demandada fuera del litigio que extendió la duración de la patente, por "falta de interés jurídico". Si la expectativa de derecho de explotar una patente que pasa al dominio público, junto con la inversión realizada para llevar a cabo dicha explotación no es interés jurídico, cabe preguntarse qué sí lo es. Más aún, si en la acción de infracción, el demandado no tuvo posibilidad de defenderse en contra de dicha extensión con el argumento de la "cosa juzgada". Ese estado de indefensión, no es propio de un procedimiento justo y equitativo, que

81 Recurso de Inconformidad 608/2015 (2015) pp. 15 y 16.

82 El ECONOMista (12/09/2010).

83 El ECONOMista (12/09/2010).

84 Senado de la República, el 26 de abril de 2007. 
evite abusos tal como lo ordenan los artículos 42 y 41(1) del ADPIC. Lo anterior sin hablar de problemas de retroactividad, ya que estamos ante un procedimiento que comienza con un escrito de medidas preliminares presentado el 15 de junio de 2006, cuando el IMPI no modificó la duración de la patente sino hasta el 20 de julio de 2006.

A pesar de que tenemos un aparente y claro ganador, aquí no hubo ganadores del todo. Los infortunios legislativos no fueron resueltos en la esfera jurisdiccional. La parte demandada, nos queda claro que perdió el litigio de infracción. Pero la parte ganadora, tampoco le fue del todo bien, ya que se violaron en su perjuicio los principios de independencia de las patentes y de trato nacional. Es decir, obtuvo un término menor de protección que los nacionales mexicanos que presentaron su solicitud el mismo día en que la actora presentó su solicitud.

Este y otros litigios parecidos se pudieron haber evitado desde el comienzo en el plano legislativo. Si se pretendía proteger dichas invenciones, que de otra manera no cumplirían con el requisito de novedad, se les debió haber otorgado los 20 años que establece el artículo 23 de la Ley de la Propiedad Industrial y no sujetar su término de protección a la incertidumbre. Si así hubiese sido, tendríamos en este caso dos ganadores, no dos litigantes, Takeda y Rimsa.

\section{BIBLIOGRAFÍA CITADA}

AввотT, Frederick et al. (2007): International Intellectual Property in an Integrated World Economy (Nueva York, Aspen Publishers).

ANDreWS, Damon (2011): "Why Patentees Litigate", Columbia Science and Technology Law Review, vol. 12: pp. 219-254.

BuRGOA, Ignacio (2009): El Juicio de Amparo (México, Porrúa, cuadragésima tercera edición).

CorreA, Carlos (2007): Trade Related Aspects of Intellectual Property Rights (Oxford, Oxford University Press).

ERSLING, Jay A. y STROVE, Frederik W. (2015): “A Framework for Patent Exhaustion from Foreign Sales", Fordham Intellectual Property, Media \& Entertainment Law Journal, vol. 25: pp. 499-535.

FARRAND, James R. (2006): “Territoriality and Incentives Under the Patent Laws", Berkeley Technology Law Journal, vol. 21: pp. 1215-1291.

FiX-Zamudio, Héctor y Valencia, Salvador (2009): Derecho Constitucional Mexicano y Comparado (México, Porrúa, sexta edición).

Goldstein, Paul (2008): International Intellectual Property Law (New York, Foundation Press, segunda edición).

ILARDI, Alfredo y BLAKENEY, Michael (2004): International Encyclopedia of Intellectual Property Treaties (Oxford, Oxford University Press).

KHOURY, Amir (2012): "The End of the National Patent Office", The Intellectual Property Law Review, vol. 52: pp. 197-240.

LAPENnE, Juan (2010): "Patent Cooperation Treaty", Journal of the Patent and Trademark Office Society, vol. 92: pp. 192-207. 
Lemley, Mark A. y Moore, Kimberly A. (2004): "Ending Abuse of Patent Continuations", Boston University Law Review, vol. 84: pp. 63-123.

MCJOHn, Stephen M (2003): Intellectual Property (Nueva York, Aspen Publishers).

Mahne, Kevin (2012): "A Unitary Patent and Unified Patent Court for the European Union: An Analysis of Europe's Long Standing Attempt to Create a Supranational Patent System", Journal of the Patent and Trademark Office Society, vol. 94: pp. 162-191.

MarKham, Wesley (2011): “Terminal Illness: Curing the Patent Term Using Empirical Analysis of the Patent Globalization”, New York University Intellectual Property \& Entertainment Law Ledger, vol. 2, pp. 121-130.

Migliorini, Robert A. (2007): “Twelve Years Later: Provisional Patent Application Filing Revisited", Journal of the Patent and Trademark Office Society, vol. 89: pp. 437-455.

Mueller, Janice M. (2009): Patent Law (Nueva York, Aspen Publishers, tercera edición).

ODDI, Samuel (1987): “The International Patent System and Third World Development: Reality or Myth?" Duke Law Journal, vol. 1987: pp. 831-877.

PIL, Sung (2014): "Harmonizing Public and Private International Law: Implications of the Apple v. Samsung IP Litigation”, Journal of East Asia \& International Law, vol. 7: pp. 351-378.

PIRES, Nuno (2005): The TRIPs Regime of Patent Rights (The Hague, Kluwer Law International, segunda edición).

RaBASA, Emilio, (1955): El Artículo 14. Estudio Constitucional y El Juicio Constitucional. Origenes, Teoría y Extensión (México, Porrúa, segunda edición).

SHINALL, Michael (2012): "Priority and Disclosure: Challenges and Protections to Small Investors in a First to File World", Journal of the Patent and Trademark Office Society, vol. 94: pp. 362-400.

SOlOvy, Eric M. y KrIshnamurThy, Pavan S. (2017): “TRIPs Agreement Flexibilities and their Limitations", George Washington International Law Review, vol. 50: pp. 69-124.

TOBIAS, Peter et al. (2009): WTO Trade Related Aspects of Intellectual Property Rights (Leiden, Martinus Nijhoff Publishers).

WIPO (2018): "PCT The International Patent System”. Disponible en: http://www.wipo. int/pct/en/. Fecha de consulta: 18 de agosto de 2018.

\section{TRATADOS INTERNACIONALES CITADOS}

Acuerdo sobre los Aspectos de los Derechos de Propiedad Intelectual RelaCiONADOS CON El COMERCIO, MARRAKECH (15 DE ABRIL DE 1994).

CONVENIO de PARÍS PARA LA PROTECCIÓN DE LA PROPIEDAd INDUSTRIAL, Estocolmo (28 de septiembre de 1979).

Tratado de Cooperación en Materia de Patentes, Washington (19 de junio de 1970).

\section{NORMAS CITADAS}

LEY N 19.039 (9/03/2006), Ley de la Propiedad Industrial. 


\section{NORMAS EXTRANJERAS CITADAS}

Ley de Patentes de InVención y Modelos de Utilidad, Argentina (20/3/96).

Ley $\mathrm{N}^{\circ}$ 17.164, Derechos y Obligaciones Relativos a las Patentes De InVENCión, los Modelos de Utilidad y los DiseÑos Industriales, Uruguay (2/9/99).

Ley de la Propiedad Industrial, México (27/06/1991).

LEY DE INVENCIONES Y MARCAS (ABROGADA), México (10/2/1976).

Senado de la República, Punto de Acuerdo Propuesto por el Senador Ernesto Saro Boardman, publicado en la Gaceta del Senado de la República número: LX/1SPO-103/12370, el 26 de abril de 2007. Disponible en: http://www.senado.gob.mx/ index.php?ver=sp\&mn=2\&sm=2\&id=12370. Fecha de consulta: 25 de enero de 2018.

\section{JURISPRUDENCIA EXTRANJERA CITADA}

IMPI, Resolución 872/2006, TAKEDA V. RIMSA, 27 de febrero de 2013.

Quinto Tribunal Colegiado de Circuito del Centro Auxiliar de la Tercera Región, Amparo Directo 245/2014, 11 de septiembre de 2014.

Quinta Sala Regional Metropolitana, TFJA, expediente 14113/05-17-05-9, 2 de enero de 2006.

Quinto Tribunal Colegiado de Circuito del Centro Auxiliar de la Tercera Región, Amparo Directo 245/2014, 11 de septiembre de 2014.

Segunda Sala, Suprema Corte de Justicia de la Nación, Recurso de Inconformidad 608/2015, 12 de agosto de 2015.

Pleno de la Suprema Corte de Justicia de la Nación, Tesis: P. LXXVII/99, Semanario Judicial de la Federación y su Gaceta, Novena Época, tomo X, Noviembre de 1999, p. 46.

Segunda Sala de la Suprema Corte de Justicia de la Nación. Tesis: IV.2o.A.76 K (10a.), Gaceta del Semanario Judicial de la Federación, Libro 12, Noviembre de 2014, Tomo IV, p. 2918. 